\title{
METABOLISMO DE CARBOIDRATOS EM ERITRÓCITOS DE PEIXES: COMPARTIMENTALIZAÇ̃̃O DA GLICOSE SANGÜÍNEA
}

\section{A. MEDEIROS ${ }^{1}$; E. RODRIGUES ${ }^{2}$; R. ROSA ${ }^{3}$; M. BACILA ${ }^{1}$}

Estação Antártica Comandante Ferraz - Ilha do Rei George - Antártica. ${ }^{1}$ Laboratório de Piscicultura - Setor de Ciências Agrárias Universidade Federal do Paraná. ${ }^{2}$ Faculdade de Ciências Farmacêuticas - USF. ${ }^{3}$ Pontifícia Universidade Católica - PR

O estudo dos níveis de glicose plasmática em peixes tem sido objeto de vários trabalhos, enfocando o efeito da temperatura, a permeabilidade da membrana eritrocitária à glicose, o stress e a influência do estado fisiológico (FLETCHER, 1984; NIKINMAA and TIIHONEN, 1991). Como vários fatores ambientais afetam a glicemia de peixes, OTTOLENGHI et al. (1995) trabalharam com catfish aclimatados em temperaturas entre $24^{\circ} \mathrm{C}$ à $36^{\circ} \mathrm{C}$, verificando que em baixas temperaturas os níveis de glicose sangüínea são mais elevados. RODRIGUES et al. (1994) estudando a compartimentalização de glicose em sangue de peixes Notothenidae da região Antártica, encontraram glicose sangüínea distribuída de forma desigual entre o plasma e os eritrócitos. O presente estudo reúne parâmetros sangüíneos de peixes adaptados em três ambientes aquáticos distintos: peixes antárticos, peixes marinhos de região subtropical e peixes tropicais de água doce. Amostras de sangue colhidas com vacuntainer heparinizado e contendo fluoreto através de punção da veia caudal dos peixes. Alíquotas do sangue foram centrifugadas a $1.500 \mathrm{x} g$ e o plasma utilizado para determinação de glicose. Alíquotas de sangue total foram utilizadas na determinação do hematócrito - método clássico de centrifugação, hemoglobina método da cianometahemoglobina e de glicose no plasma e sangue total pelos métodos da glicose oxidase e orto-toluidina. A tabela 1 reúne dados referentes a 7 espécies de peixes.

Tabela 1. Parâmetros sangüíneos de peixes antárticos, peixes marinhos de região subtropical e peixes de água doce de região tropical.

\begin{tabular}{l|l|l|l|l}
\hline \multicolumn{1}{c}{ Peixes } & \multicolumn{1}{c|}{ HT $(\%)$} & \multicolumn{1}{c}{ Hb $(\mathrm{g} / \mathrm{dL})$} \\
\cline { 2 - 4 } & & \multicolumn{1}{c}{ Plasma } & Sangue Total & \\
\hline Notothenia neglecta $(\mathrm{n}=25)$ & $36,2 \pm 4,0$ & $11,6 \pm 8,7$ & $7,7 \pm 5,4$ & $7,6 \pm 0,7$ \\
Prochilodus scropha $(\mathrm{n}=9)$ & $35,9 \pm 6,2$ & $4,0 \pm 3,4$ & $2,7 \pm 1,8$ & $12,92,9$ \\
Piaractus mesopotamicus $(\mathrm{n}=10)$ & $32,4 \pm 4,4$ & $7,3 \pm 3,9$ & $5,0 \pm 2,8$ & $12,12,6$ \\
Ahinobatos percellens $(\mathrm{n}=6)$ & $20,5 \pm 1,4$ & $3,8 \pm 1,4$ & $3,0 \pm 1,2$ & $5,4 \pm 0,5$ \\
Netuna barba $(\mathrm{n}=9)$ & $24,4 \pm 3,6$ & $3,3 \pm 1,4$ & $2,5 \pm 0,9$ & $5,7 \pm 1,6$ \\
Mugil sp $(\mathrm{n}=2)$ & $36,2 \pm 1,0$ & $14,5 \pm 7,5$ & $10,0 \pm 5,5$ & $9,2 \pm 0,4$ \\
Menticirrhus litoralis $(\mathrm{n}=3)$ & $25,8 \pm 5,6$ & $4,2 \pm 0,2$ & $3,1 \pm 0,5$ & $6,3 \pm 0,9$ \\
\hline
\end{tabular}

As espécies estudas, semelhante à maioria dos teleosteos, apresenta baixa permeabilidade eritrocitária à glicose, concentrando a glicose do sangue, quase que exclusivamente no plasma.

Apoio: CNPq - PROANTAR . 